\title{
Effects of maternal ageing and dietary antioxidant supplementation on ovulation, fertilisation and embryo development in vitro in the mouse
}

\author{
Juan Tarín*, Jorge Ten, Francisco J. Vendrell, \\ Maria N.M. de Oliveira, Antonio Cano
}

Department of Paediatrics, Obstetrics and Gynaecology, Faculty of Medicine, University of Valencia, Avda. Blasco Ibañez 17, 46010 Valencia, Spain

(Received 10 July 1998; accepted 5 October 1998)

\begin{abstract}
The present study aims to ascertain whether dietary supplementation with a mixture of vitamins $\mathrm{C}$ and $\mathrm{E}$ may prevent the maternal-age-associated decrease in both the number of ovulated oocytes after exogenous ovarian stimulation and embryo development in vitro in the mouse. Experimental females were fed a standard diet supplemented with i) high doses of vitamins $\mathrm{C}$ and $\mathrm{E}$ from the first day of weaning until 12 or 40 weeks of age; or ii) moderate doses of vitamins $\mathrm{C}$ and $\mathrm{E}$ from the first day of weaning until 12 weeks of age or from 22 to 33 weeks of age. The age-related reduction in ovulation rate was partially prevented by supplementing diet with high doses of vitamins $C$ and $\mathrm{E}$ from the first day of weaning. Shorter periods of treatment and lower doses of vitamins $\mathrm{C}$ and $\mathrm{E}$ were also efficient in preventing the maternal-age-associated reduction in ovulation rate after exogenous ovarian stimulation. No effect of maternal diet on fertilisation and embryo development was observed until the blastocyst stage. Although any extrapolation to human fertility should be made with caution, these findings may have direct implications for preventing or delaying maternal-age-associated infertility in humans. 1 Inra/Elsevier, Paris.
\end{abstract}

dietary antioxidant supplementation / embryo development / in vitro fertilisation / maternal ageing / ovulation

Résumé - Effet de l'âge maternel et de l'ajout d'anti-oxydants au régime alimentaire, sur l'ovulation, la fécondation et le développement embryonnaire in vitro chez la souris. L'objectif de cette étude est de vérifier que l'adjonction quotidienne d'un mélange de vitamines $C$ et $E$ peut prévenir la diminution du nombre d'ovocytes ovulés après stimulation ovarienne observée avec l'âge, ainsi que la diminution du taux de développement des ovocytes après fécondation. Les souris ont reçu un régime standard auquel ont été ajoutées i) des doses élevées de vitamines $\mathrm{C}$ et $\mathrm{E}$ depuis le sevrage jusqu'à 12 ou 40 semaines; ii) des doses modérées de vitamines $C$ et $E$ du sevrage à

* Correspondence and reprints

E-mail: tarinjj@uv.es 
22 semaines ou entre 22 et 33 semaines. La réduction du nombre d'ovocytes récoltés avec l'âge ( 40 semaines) est partiellement prévenue par l'addition de doses élevées de vitamines $\mathrm{C}$ et $\mathrm{E}$ à partir du sevrage. Un effet similaire a été observé lors de périodes de traitements plus courtes avec des doses modérées. En revanche, aucun effet n'a été observé sur le taux de fécondation et le développement embryonnaire jusqu'au stade de blastocyste. Ces résultats doivent être interprétés avec précaution mais pourraient avoir des implications directes sur la prévention de la stérilité associée au vieillissement chez la femme. (C) Inra/Elsevier, Paris.

développement embryonnaire / fécondation in vitro / âge maternel / ajout d'anti-oxydants au régime alimentaire / ovulation

\section{INTRODUCTION}

It is well-known that maternal ageing is associated with loss of oocyte/embryo via bility and reproductive potential. In particular, maternal ageing is linked to i) increased percentages of chromosome fragmentation and aneuploidy; ii) non-extrusion of the first polar body; iii) spontaneous parthenogenetic activation of oocytes; iv) cytoplasmic fragmentation; v) polyspermy; vi) abnormal development of embryos; and vii) increased embryonic mortality (for reviews, see Vom Saal et al. [30] and Tarín [25]). In order to explain the effects of maternal ageing on mammalian oocytes/embryos, a mechanism based on the 'the oxygen radical-mitochondrial injury hypothesis of ageing' has been recently suggested $[24,25]$. This mechanism attributes a key role in the senescent process to oxygen radical damage to mitochondrial DNA, proteins and lipids in primary oocytes and/or surrounding ovarian cells during the nuclear arrest at the diplotene stage of the first meiotic division. Accumulated oxidative damage to mitochondria may increase the production of reactive oxygen species (ROS) by the electron transport chain and decrease the number of functionally intact mitochondria, causing a drop in ATP levels. The higher production of ROS by defective mitochondria may increase intracellular oxidised glutathione (GSSG)/reduced glutathione (GSH) ratio which, among others cellular functions, may cause impairment of $\mathrm{Ca}^{2+}$ transport and sub- sequent perturbation of intracellular $\mathrm{Ca}^{2+}$ homeostasis. All these variables may have profound effects on oocyte/embryo cytoskeletal fibres, balance of protein kinase/phosphatase activity, and synthesis of proteins and other macromolecules including RNA and DNA (for review, see Tarín [25]).

The oxidative stress hypothesis of Tarín $[24,25]$ is attractive because it provides a rationale for preventing age-associated aneuploidy and infertility by administration of antioxidants. Epidemiologic studies suggest an association between increased intake of antioxidants and reduced mortality and/or morbidity from cancer, cardiovascular disease, stroke, cataracts, neurological pathologies, and decay of immune system either with age or due to chronic inflammatory diseases (for review, see Ames et al. [1]). On the other hand, although we have observed in the mouse that dietary supplementation with high doses of vitamins $C$ and $E$ decreases the number of spermatozoa/mg epididymis and increases the percentage of spermatozoa with misshapen heads distended in the distal part [28], this antioxidant diet may protect against maternal-age-associated aneuploidy and diploidy in mouse oocytes [27]. In the present study, we aim to ascertain whether dietary supplementation from the weaning with high doses of vitamins $\mathrm{C}$ and $E$ prevents the maternal-age-associated reduction in ovulation rate after exogenous ovarian stimulation; and, if so, to determine the effectiveness of shorter periods of treat- 
ment and lower doses of vitamins $\mathrm{C}$ and $\mathrm{E}$. Furthermore, we aim to ascertain the effects of supplemental intake of vitamins $C$ and $E$ on maternal-age-associated decrease in oocyte/embryo viability.

\section{MATERIALS AND METHODS}

\subsection{Animals, dietary supplements and oocyte retrieval}

F1 hybrid mice (C57BL/6JIco female $\mathrm{X}$ CBA/JIco male) (Criffa, Santa Perpetua de la Mogoda, Barcelona, Spain) were maintained on a 07:00 to $21: 00$ hours light cycle at $20^{\circ} \mathrm{C}$. Males were fed a standard diet [containing (calculated $/ \mathrm{kg}$ diet) carbohydrates $(570 \mathrm{~g})$, lipids $(30 \mathrm{~g})$, proteins $(160 \mathrm{~g})$, minerals $(50 \mathrm{~g})$, fibres $(50 \mathrm{~g})$, vitamin A (9000 iu), D3 (1 $000 \mathrm{iu})$, B1 (7.5 mg), B2 (6 mg), B6 (5 mg), B12 (25 mg), E (50 mg), $\mathrm{K} 3(1.2 \mathrm{mg})$ and $\mathrm{PP}(30 \mathrm{mg})$, acid pantotenic $(15 \mathrm{mg})$ and choline (750 mg)] (diet IPM-R20, Letica, Barcelona, Spain) and tap water ad libitum. Females were randomly allocated to either a control or an experimental group. In the control group, females were fed the same standard diet as males. In a first series of trials, experimental females were fed the standard diet supplemented with an antioxidant mixture of high doses of vitamin C (Basf, Grenaa, Denmark; $10 \mathrm{~g} \cdot \mathrm{kg}^{-1}$ diet) and vitamin $\mathrm{E}$ (Kirschpharma GmbH, Salzgtter, Germany; $0.6 \mathrm{~g} \cdot \mathrm{kg}^{-1}$ diet) from the first day of weaning ( $21 \mathrm{~d}$ of age) until they were autopsied at 12 weeks of age (young females) or 40 weeks of age (middle-aged females). Assuming a daily food intake of $4 \mathrm{~g} /$ mouse and a body weight of $25 \mathrm{~g}$ /mouse (average figures for adult mice from this particular F1 hybrid strain), the average daily intake of dietary supplements of vitamins $\mathrm{C}$ and $\mathrm{E}$ (without taking into account the basal content of vitamin $E$ in the standard diet) was $1600 \mathrm{mg}$ (1 $600 \mathrm{iu}$ ) vitamin C and $96 \mathrm{mg}$ (96 iu) vitamin $\mathrm{E} / \mathrm{kg}$ body weight. This particular mixture of vitamins was chosen based on previous studies demonstrating a protective effect of this particular antioxidant mixture against: i) glutathione (GSH) oxidation in blood and in mitochondria from the liver and brain of aged rats [5]; ii) zidovudineinduced molecular and ultrastructural oxidative damage to muscle mitochondria of male OF1 mice [6]; and iii) maternal-age-associated disturbances in chromosomal distribution in the MII spindle and chromosomal segregation during the first meiotic division of mouse oocytes [27].
In a second series of trials, experimental females were fed the standard diet supplemented with moderate doses of vitamin C (Basf; $0.025 \mathrm{~g} \cdot \mathrm{kg}^{-1} \mathrm{diet}$ ) and vitamin $\mathrm{E}$ (Kirschpharma $\mathrm{GmbH} ; 0.06 \mathrm{~g} \cdot \mathrm{kg}^{-1}$ diet) from the first dof weaning until they were killed at 12 weeks of age (young females) or from 22 weeks of age until they were killed at 33 weeks of age (middle-aged females). Such an antioxidant diet resulted in an average daily intake (without taking into account the basal content of vitamin $\mathrm{E}$ in the standard diet) of $4 \mathrm{mg}$ (4iu) vitamin C and $9.6 \mathrm{mg}$ (9.6 iu) vitamin $\mathrm{E} / \mathrm{kg}$ body weight. These doses are analogous to those used in humans to protect sperm from endogenous oxidative DNA damage (250 $\mathrm{mg} / \mathrm{d}$ of vitamin C [10]) and improve invitro function of spermatozoa as assessed by the zona binding test $(600 \mathrm{mg} / \mathrm{d}$ of vitamin E [13]).

Females were superovulated by an intraperitoneal injection of 10 iu pregnant mare's serum gonadotrophin (PMSG) (Folligon; Intervet-International, Boxmeer, Holland) followed $48 \mathrm{~h}$ later by $10 \mathrm{iu}$ of hCG (Chorulon; Intervet-International). The timing of PMSG and hCG injections was scheduled at 20:00 hours. One control and one experimental female from both young and middle-aged mice were killed by cervical dislocation at $14 \mathrm{~h}$ after hCG injection. Oviducts were excised and placed into $2 \mathrm{~mL}$ medium M2 [19] supplemented with $4 \mathrm{mg}$ BSA (Fraction V, Sigma Chemical Co., St. Louis, MO, USA)/mL. Oocytes enclosed in cumulus masses were released from the ampullae, washed, and transferred directly to insemination droplets.

\subsection{Fertilisation and embryo development in vitro}

In each experiment, one 12-to 16-week-old F1 hybrid male was killed $2 \mathrm{~h}$ before insemination. Both cauda epididymes were excised and placed into $1 \mathrm{~mL}$ medium T6 [19] supplemented with $15 \mathrm{mg} \mathrm{BSA} / \mathrm{mL}$. Ten minutes later, the caudae were discarded and the sperm solution adjusted to a concentration of $10 \times 10^{6}$ spermatozoa/mL. Spermatozoa were then incubated until insemination in $20 \mu \mathrm{L}$ droplets overlaid with mineral oil (light white oil; Sigma Chemical Co.) in an atmosphere of $5 \% \mathrm{CO}_{2}$ in air at $37{ }^{\circ} \mathrm{C}$. Each couple of cumulus-oocyte complexes from four different females were transferred to one sperm droplet. Cumulus-oocyte complexes were distributed in a $2 \times 2$ factorial design established according to whether females were young or middle-aged and fed a control or antioxidant diet. 
At $6 \mathrm{~h}$ after insemination, oocytes were washed, transferred, and incubated in groups of 10 in $20 \mu \mathrm{L}$ droplets of medium M16 [31] supplemented with $4 \mathrm{mg} \mathrm{BSA} / \mathrm{mL}$. Oocytes were assessed to be fertilised if they extruded a second polar body and had two pronuclei at $8 \mathrm{~h}$ after insemination. The remaining oocytes were classified as unfertilised or degenerated. Oocyte degeneration at $8 \mathrm{~h}$ post-insemination was shown by cellular fragmentation, oocyte shrinkage, and/or milky, dark or granular appearance of the cytoplasm. Embryo development was recorded every $24 \mathrm{~h}$ for $5 \mathrm{~d}$ (approximately $120 \mathrm{~h}$ after insemination). Hatching blastocysts were those that had partially or totally escaped from the zona pellucida.

\subsection{Fluorescence staining and counting of nuclei}

As an undetermined number of cells within mouse blastocysts undergoes programmed cell death [4], embryos from some experiments were fixed and their nuclei labelled at $81 \mathrm{~h}$ post-insemination. Only embryos that had reached the 16-cell or early blastocyst stage were entered into the study. The zona pellucidae were removed with acid Tyrode's ( $\mathrm{pH} 2.4$ ). Embryos were then fixed and labelled overnight in absolute alcohol containing $94 \mu \mathrm{M}$ bisbenzimide (Hoechst 33258; Sigma Chemical Co.) at $4{ }^{\circ} \mathrm{C}$. Labelled embryos were washed for $1 \mathrm{~h}$ in absolute alcohol before examination. For counting the number of nuclei, embryos were mounted on microscope slides in glycerol beneath a coverslip and carefully squashed using a pencil eraser. Nuclei showing metaphase chromosomes were counted as single cells. The mitotic index of each embryo was defined as the percentage of number of metaphases/total number of cells.

\subsection{Statistical analysis}

Two-way analysis of variance (ANOVA) test and $t$-test were applied for comparisons of means. In order to stabilise variances, proportions were transformed to arcsine before carrying out mean comparisons. When Kolmogorov-Smirnov onesample test showed that data did not fit a normal distribution (such as mitotic index at $81 \mathrm{~h}$ post-insemination), non-parametric Mann-Whitney test was applied for testing the hypothesis that two independent samples had the same dis- tribution. Significance was defined as $P \leq 0.05$. The entire statistical analysis was carried out using the Statistical Package for Social Sciences (SPSS).

\section{RESULTS}

Table I shows the effect on ovulation, fertilisation and embryo development of both maternal ageing and dietary supplementation with an antioxidant mixture of high doses of vitamins $\mathrm{C}$ and $\mathrm{E}$ from the first day of weaning until 40 weeks of age. Maternal ageing was associated with a decrease in total number of oocytes ovulated $(P \leq 0.0005)$ and number of cells at $81 \mathrm{~h}$ post-insemination $(P \leq 0.01)$ in both control and treated mice. The age-related reduction in ovulation rate was, however, partially $(P \leq 0.05)$ prevented by supplementing diet with high doses of vitamins $C$ and $E$. No significant effect of maternal diet on fertilisation, percentage of degenerated oocytes at $8 \mathrm{~h}$ after insemination and embryo development until the blastocyst stage was observed.

In order to test whether a shorter period of treatment and lower doses of vitamins $\mathrm{C}$ and $\mathrm{E}$ before the conception cycle can also prevent the maternal-age-associated reduction in ovulation rate, experimental females were fed the standard diet supplemented with relatively low doses of vitamins $C$ and E from 22 weeks of age until they were autopsied at 33 weeks of age. At this point, control females ovulated a number of oocytes $(22.1 \pm 3.3 ; n=10)$ in between 12-weekold mice $(35.9 \pm 2.9 ; n=20 ; t$-test; $P \leq 0.05)$ and 40-week-old mice $(10.8 \pm 2.4 ; n=10$; $t$-test; $P \leq 0.05)$. Two-way ANOVA test showed a significant $(P \leq 0.005)$ effect of maternal ageing on percentage of degenerated oocytes at $8 \mathrm{~h}$ after insemination (table II). No significant effect of maternal ageing and/or diet on both number of oocytes recovered and embryo development was observed in these experiments. Notwithstanding, two-sample $t$-test showed that the 


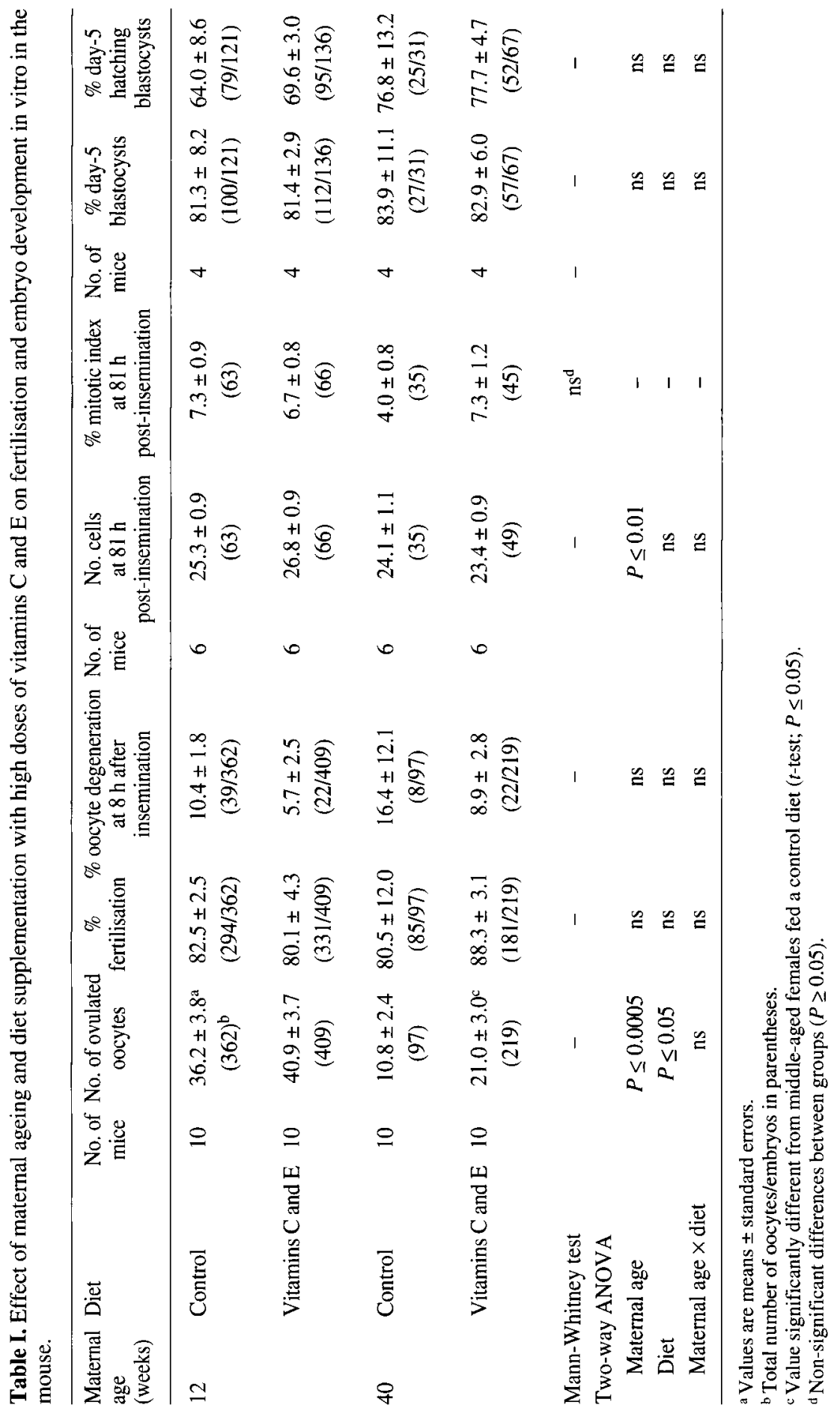




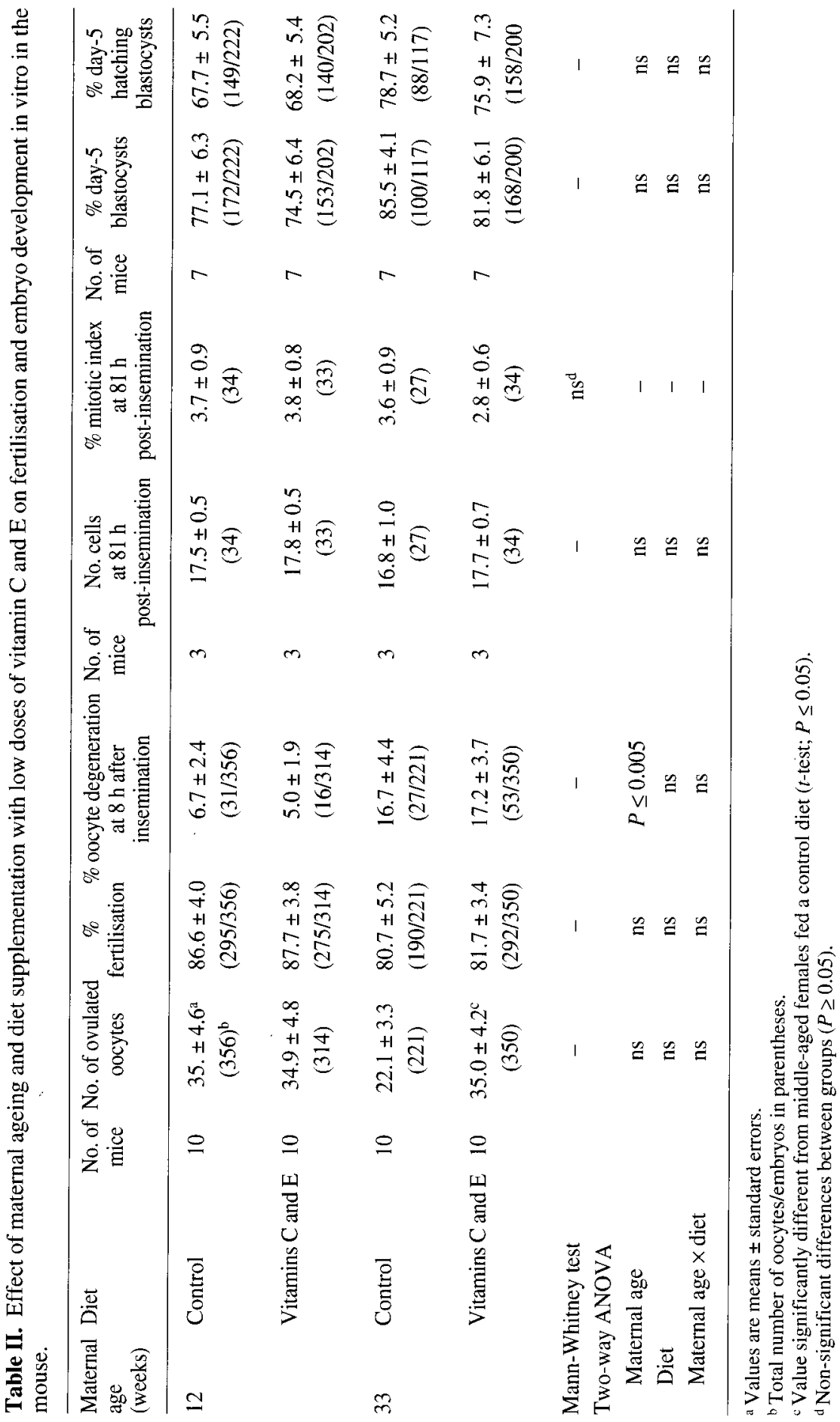


number of oocytes ovulated by middle-aged females fed the antioxidant diet was significantly $(P \leq 0.05)$ higher when compared to middle-aged females fed a control diet.

\section{DISCUSSION}

The present results show that dietary supplementation with a mixture of high doses of vitamins $C$ and $E$ from the first dof weaning until 40 weeks of age prevents or slows down the maternal-age-associated decrease in ovulation rate after exogenous ovarian stimulation. The protective effect of vitamins $\mathrm{C}$ and $\mathrm{E}$ on number of oocytes recovered was demonstrated also when using moderate doses (within the range used in humans) of vitamins $\mathrm{C}$ and $\mathrm{E}$ for a shorter period of time.

The enhancing effect of vitamins $\mathrm{C}$ and $\mathrm{E}$ on ovulation rate found in the present paper is in agreement with other lines of evidence from the rainbow trout showing a positive correlation between dietary levels of ascorbyl monophosphate (an ascorbic acid ester with a biological activity comparable to that of L-ascorbic acid) and number of eggs produced [3]. Furthermore, it has been reported that oral administration of daily $400 \mathrm{mg}$ of ascorbic acid enhances the ovulation-inducing effect of clomiphene in anovulatory women [12]. The present study shows no effect of diet on ovulation rate in young females of 12 weeks of age, i.e. when an agerelated decrease in number of oocytes recovered is not yet evidenced. These results, therefore, suggest that dietary antioxidant supplementation with vitamins $\mathrm{C}$ and $\mathrm{E}$ does not affect the mechanism of follicular recruitment and ovulation induced by exogenous ovarian stimulation. It rather seems to delay the age-associated depletion of oocytes in ovaries by follicular atresia.

Recent studies suggest that atresia of ovarian follicles is induced through apoptotic cell death of granulosa cells (for review, see Billig et al. [2]. Among many other fac- tors, programmed cell death or apoptosis of granulosa cells may be induced by both oxidative stress $[17,29]$ and low production of oestrogen by follicles (for review, see Billig et al. [2]). It has been reported that dietary supplementation with high doses of vitamins $C$ and $E$ (the same cocktail used in the present study) protects against GSH oxidation in blood and mitochondria from livers and brains of middle-aged rats [6]. Vitamin $E$ has also been implicated in preventing GSH oxidation in heart cells of guinea pigs [21] and protecting steroidogenic enzymes of guinea pig [22] and human [23] adrenal microsomes from oxidative inactivation. Moreover, granulosa cell apoptosis in rat ovarian follicles deprived of tropic hormone support is prevented by treatment in vitro with superoxide dismutase (SOD), $\mathrm{N}$-acetyl-L-cysteine, catalase or ascorbic acid [29]. This body of evidence suggests, therefore, that dietary supplementation with vitamins $\mathrm{C}$ and $\mathrm{E}$ may decrease the proportion of follicles undergoing follicular atresia by counteracting the potential generation of oxidative stress in oocytes and/or granulosa cells from ageing females. A decreased rate of follicular atresia may delay the age-related depletion in follicles that have undergone transition to the antral stage of development in the mammalian ovary (for references see, Tilly and Tilly [27, 29]), and so maintain for longer the ovulation rate of middle-aged females at levels similar to those found in young females. However, arguing against the likely importance of the antioxidant properties of the mixtures of vitamins $C$ and $E$ used in the present study is the fact that monovalent substitution of thiol groups fails to suppress Fas/APO-1/CD95-induced apoptosis in mouse thymocytes [16]. It should be borne in mind at this point that apoptosis of rat granulosa cells from atretic follicles is associated with expression of Fas antigen and Fas ligand on granulosa cells [14] and Fas ligand on oocytes [11].

An alternative mechanism to explain the protective effect of vitamins $C$ and $E$ on the 
maternal-age-associated decrease in number of oocytes collected after exogenous ovarian stimulation may be related to the ageing of the hypothalamic-pituitary system (or brain) rather than the ovary or oocytes. In fact, in old animals, the hypothalamus cannot tightly regulate the secretion of gonadotrophins from the anterior pituitary. This damage in the regulative function of the hypothalamus causes transient increases in the levels of LH and FSH which, in turn, may accelerate depletion of the primordial follicle pool (cited by Flaws et al. [9]). Dietary antioxidant supplementation with vitamins $C$ and $E$ may protect the hypothalamic-pituitary system from free radical damage and so 'age' less rapidly, maintaining a lower (less damaging) baseline level of LH and FSH for longer. Further studies are needed to ascertain whether the circulating levels of LH and FSH in middle-aged mice fed an antioxidant diet are decreased when compared to control mice.

In contrast to other studies demonstrating an increased proportion of abnormal preimplantation embryos in middle-aged mice (for review, see Nelson and Felicio [18] and Vom Saal et al. [30]), the present study shows no effect of maternal ageing on embryo morphology and percentage of embryos reaching the blastocyst stage on day 5. Although inter-strain variability in the rate of ageing undergone by the reproductive system may play an important role, other factors such as the age at which females were killed should be taken into account for explaining discrepancies between studies. In fact, the oldest females used in the present study were 40 weeks of age, whereas other authors (T.A. Parkening, I.F. Lau, S.K. Saksena and M.C. Chang) used older mice of 11.5 to 15.5 months of age (for review, see Nelson and Felicio [18]). Notwithstanding, 40-weekold females from our study not only showed a reduction in ovulation rate $(P \leq 0.0005)$ but also decreased numbers of cells at $81 \mathrm{~h}$ after insemination $(P \leq 0.01)$, signs of agerelated loss of reproductive potential.
In conclusion, the present study shows that some characteristics of the female reproductive system during reproductive senescence such as reduction in number of oocytes recovered after exogenous ovarian stimulation, can be partially prevented by supplementing diet with a mixture of either high or moderate doses of vitamins $\mathrm{C}$ and $\mathrm{E}$. Although any extrapolation to human fertility should be made with caution [in contrast to mice, human beings cannot synthesise ascorbic acid because they lack the liver enzyme L-gulono-lactone oxidase (cited by Luck et al. [15])], these findings may have direct implications for preventing or delaying maternal-age-associated infertility in humans. As in the mouse model, the store of human ovarian oocytes and primordial follicles reaches a maximum before birth and declines exponentially thereafter until the menopause [7]. Likewise, the number of oocytes recovered after exogenous ovarian stimulation with gonadotrophins decreases significantly with maternal age [8]. Thus, dietary allowance of vitamins $C$ and $E$ may slow down age-associated ovarian depletion of oocytes and prolong a woman's fertile life. However, we should bear in mind that antioxidant therapy may be a doubleedged sword with negative and undesirable effects on fertility and pregnancy if a safety threshold dosage of antioxidants is surpassed (for review, see Tarín et al. [26]). In fact, high doses of dietary antioxidants may have pro-oxidant effects or interfere with the physiological properties of reactive oxygen species on uterine environment, oocyte maturation and ovulation, and corpus luteum function and regression [20].

\section{ACKNOWLEDGEMENTS}

We would like to thank Dr J. Mondejar and Dr F. Picazo and an anonymous referee for helping us to translate the summary section from English into French. This study was supported by a grant from the 'Ministerio de Sanidad y Consumo' to A.C. (FIS 93/0680). 


\section{REFERENCES}

[1] Ames B.N., Shigenaga M.K., Hagen T.M., Oxidants, antioxidants, and the degenerative diseases of aging, Proc. Natl. Acad. Sci. USA 90 (1993) 7915-7922.

[2] Billig H., Chun S.Y., Eisenhauer K., Hsueh A.J.W., Gonadal cell apoptosis: hormone-regulated cell demise, Hum. Reprod. Update 2 (1996) 103-117.

[3] Blom J.H., Dabrowski K., Reproductive success of female rainbow trout (Oncorhynchus mykiss) in response to graded dietary ascorbyl monophosphate levels, Biol. Reprod. 52 (1995) 1073-1080.

[4] Brison D.R., Schultz R.M., Apoptosis during mouse blastocyst formation: evidence for a role for survival factors including transforming growth factor a, Biol. Reprod. 56 (1997) 1088-1096.

[5] De la Asunción J.G., Millán A., Plá R., Bruseghini L., Esteras A., Pallardó F.V., Sastre J., Viña J., Mitochondrial glutathione oxidation correlates with age-associated oxidative damage to mitochondrial DNA, FASEB J. 10 (1996) 333-338.

[6] De la Asunción J.G., Del Olmo M.L., Sastre J., Millán A., Pellín A., Pallardó F.V., Viña J., AZT treatment induces molecular and ultrastructural oxidative damage to muscle mitochondria. Prevention by antioxidant vitamins, J. Clin. Invest. 102 (1998) 4-9.

[7] Faddy M.J., Gosden R.G., Gougeon A., Richardson J., Nelson J.F., Accelerated disappearance of ovarian follicles in mid-life: implications for forecasting menopause, Hum. Reprod. 7 (1992) 1342-1346.

[8] FIVNAT, In-vitro fertilization: influence of women's age on pregnancy rates, Hum. Reprod. 5 (1990) 56-59.

[9] Flaws J.A., Abbud R., Mann R.J., Nilson J.H., Hirshfield A.N., Chronically elevated luteinizing hormone depletes primordial follicles in the mouse ovary, Biol. Reprod. 57 (1997) 1233-1237.

[10] Fraga C.G., Motchnik P.A., Shigenaga M.K., Helbock H.J., Jacob R.A., Ames B.N., Ascorbic acid protects against endogenous oxidative DNA damage in human sperm, Proc. Natl. Acad. Sci. USA 88 (1991) 11003-11006.

[11] Hakuno N., Koji T., Yano T., Kobayashi N, Tsutsumi O., Taketani Y., Nakane P.K., Fas/ APO-1/CD95 system as a mediator of granulosa cell apoptosis in ovarian follicle atresia, Endrocrinology 137 (1996) 1938-1948.

[12] Igarashi M., Augmentative effect of aserbic acid upon induction of human ovulation in clomiphene-ineffective anovulatory women, Int. J. Fertil. 22 (1977) 168-173.
[13] Kessopoulou E., Powers H.J., Sharma K.K. Pearson M.J., Russell J.M., Cooke I.D., Barratt C.L.R., A double-blind randomized placebo cross-over controlled trial using the antioxidant vitamin $\mathrm{E}$ to treat reactive oxygen species associated male infertility, Fertil. Steril. 64 (1995) 825-831.

[14] Kim J.M., Boone D.L., Auyeung A., Tsang B.K., Granulosa cell apoptosis induced at the penultimate stage of follicular development is associated with increased levels of Fas and Fas ligand in the rat ovary, Biol. Reprod. 58 (1998) $1170-1176$.

[15] Luck M.R., Jeyaseelan I., Scholes R.A., Ascorbic acid and fertility, Biol. Reprod. 52 (1995) 262-266.

[16] Marchetti P., Decaudin D., Macho A., Zamzami N., Susin S.A., Kroemer G., Redox regulation of apoptosis: impact of thiol oxidation status on mitochondrial function, Eur. J. Immunol. 27 (1997) 289-296.

[17] Margolin Y., Aten R.F., Behrman H.R., Antigonadotropic and antisteroidogenic actions of peroxide in rat granulosa cells, Endocrinology 127 (1990) 245-250.

[18] Nelson J.F., Felicio L.S., Reproductive aging in the female: an etiological perspective, Rev. Biol. Res. Aging 2 (1985) 251-314.

[19] Quinn P., Barros C., Whittingham D.G., Preservation of hamster oocytes to assay the fertilizing capacity of human spermatozoa, J. Reprod. Fertil. 66 (1982) 161-168.

[20] Riley J.C.M., Behrman H.R., Oxygen radicals and reactive oxygen species in reproduction, Proc. Soc. Exp. Biol. Med. 198 (1991) 781-791.

[21] Rojas C., Cadenas S., López-Torres M., PérezCampo R., Barja G., Increase in heart glutathione redox ratio and total antioxidant capacity and decrease in lipid peroxidation after vitamin $\mathrm{E}$ dietary supplementation in guinea pigs, Free Rad. Biol. Med. 21 (1996) 907-915.

[22] Staats D.A., Lohr D.P., Colby H.D., Effects of tocopherol depletion on the regional differences in adrenal microsomal lipid peroxidation and steroid metabolism, Endocrinology 123 (1988) 975-980.

[23] Takayanagi R., Kato K.I., Ibayashi H., Relative inactivation of steroidogenic enzyme activities of in vitro vitamin E-depleted human adrenal microsomes by lipid peroxidation, Endrocrinology 119 (1986) 464-469.

[24] Tarín J.J., Aetiology of age-associated aneuploidy: a mechanism based on the "free radical theory of ageing', Mol. Hum. Reprod. 1, Hum. Reprod. 10 (1995) 1563-1565.

[25] Tarín J.J., Potential effects of age-associated oxidative stress on mammalian oocytes/embryos, Mol. Hum. Reprod. 2 (1996) 717-724. 
[26] Tarín J.J., Brines J., Cano A., Antioxidants may protect against infertility, Hum. Reprod. 13 (1998) 1415-1424.

[27] Tarín J.J., Vendrell F.J., Ten J., Cano A., Antioxidant therapy counteracts the disturbing effects of diamide and maternal ageing on meiotic division and chromosomal segregation in mouse oocytes, Mol. Hum. Reprod. 4 (1998) 281-288.

[28] Ten J., Vendrell F.J., Cano A., Tarín J.J., Dietary antioxidant supplementation did not affect declining sperm function with age in the mouse but did increase head abnormalities and reduced sperm production, Reprod. Nutr. Dev. 37 (1997) $481-492$.
[29] Tilly J.L., Tilly K.I., Inhibitors of oxidative stress mimic the ability of follicle-stimulating hormone to suppress apoptosis in cultured rat ovarian follicles, Endocrinology 136 (1995) 242-252.

[30] Vom Saal F.S., Finch C.E., Nelson J.F., Natural history and mechanisms of reproductive aging in humans, laboratory rodents, and other selected vertebrates, in: Knobil E., Neill J.D. (Eds.), The Physiology of Reproduction, 2nd ed., Raven Press, New York, 1994, pp. 1213-1314.

[31] Whittingham D.G., Culture of mouse ova, J. Reprod. Fertil. 14 (1971) 7S-21S. 